\title{
A Low-cost Sulfate-based All Iron Redox Flow Battery
}

Sicen Yu, Xiujun Yue, John Holoubek, Xing Xing, Eric Pan, Tod Pascal, Ping Liu*

Sicen Yu, Xing Xing

Program of Materials Science, University of California San Diego, La Jolla, California 92093, United States

Xiujun Yue, John Holoubek, Tod Pascal, Ping Liu

Department of NanoEngineering, University of California San Diego, La Jolla, California 92093, United States

Eric Pan

The Bishop's School, La Jolla, California 92037, United States

Corresponding author

Ping Liu

Department of NanoEngineering, University of California San Diego, La Jolla, California 92093, United States

Email: piliu@eng.ucsd.edu 


\begin{abstract}
Redox flow batteries (RFBs) are promising choices for stationary electric energy storage. Nevertheless, commercialization is impeded by high-cost electrolyte and membrane materials. Here, we report a low-cost all-iron RFB that features inexpensive $\mathrm{FeSO}_{4}$ electrolytes, microporous membrane along with a glass fiber separator. The addition of 0.1 м 1-ethyl-3-methylimidazolium chloride (EMIC) overcomes the low solubility of $\mathrm{FeSO}_{4}$ in water which is raised to $2.2 \mathrm{~m}$. DFT calculations demonstrate that $\mathrm{EMI}^{+}$can strengthen the interaction between sulfate anions and water molecules. This electrolyte composition also allows both anode and cathode reactions to operate without actively maintaining a $\mathrm{pH}$ gradient between them, thus eliminating the need for expensive ion exchange membranes. The all-iron RFB demonstrates stable operation at a current density of $20 \mathrm{~mA} \mathrm{~cm}^{-2}$ for more than 800 cycles via a simple, periodic regeneration process. Furthermore, the system cost of $\mathrm{FeSO}_{4} / \mathrm{EMIC}$ RFBs is projected to be $\$ 50$ per $\mathrm{kWh}$ due to its low-cost active materials and the inexpensive microporous membrane. This low-cost, highconcentration all-iron RFB is a promising stationary energy-storage system for storing renewable energy.
\end{abstract}

Keywords: All-iron flow battery, $\mathrm{FeSO}_{4}$, High concentration, Low cost, DFT calculations

\title{
1. Introduction
}

Among the electrochemical energy storage options for renewable energy storage, redox flow batteries (RFB) hold distinct advantages over lithium-ion and other competing systems in terms of their prospective scalability, safety, material abundance, and cycle life [1,2]. For example, all-vanadium redox flow batteries (VRFBs) are quite mature with commercialization underway $[3,4]$. The advantage of these systems lies in their ability to mitigate crossover-related irreversible performance losses owing to identical metal species in the catholyte and anolyte, which contain an optimized mixture of sulfates and chlorides, further reducing cost and improving energy density [5-7]. However, the commercialization process is hindered by its 
expensive membrane and vanadium-based electrolyte, which contribute to $7 \%$ and $47 \%$ of the total system cost, respectively (including tanks, pumps, piping, power electronics, etc.) [2,8]. Hence, developing a lowcost electrolyte utilizing cheaper redox materials along with an inexpensive membrane is critical to the future of RFB development [9-13].

In this regard, all-iron flow batteries (AIFB) are a particularly promising candidate, as iron is abundant, leading to a much lower and more stable cost compared to vanadium [14-17]. During charging, the ferrous ion $\left(\mathrm{Fe}^{2+}\right)$ is reduced to iron $\left(\mathrm{Fe}^{0}\right)$ on the anodic side and is oxidized to ferric ion $\left(\mathrm{Fe}^{3+}\right)$ at the cathodic side.

$$
\begin{aligned}
& \text { Anode: } \mathrm{Fe}^{2+}+2 e^{-} \rightarrow F e^{0} E^{0}=-0.44 \mathrm{~V} \text { vs } S H E \\
& \text { Cathode: } \mathrm{Fe}^{3+}+e^{-} \rightarrow F e^{2+} E^{0}=0.77 \mathrm{~V} \text { vs } S H E
\end{aligned}
$$

The common challenge of AIFB is the varying $\mathrm{pH}$ compatibility of the ferrous and ferric ions. Specifically, the catholyte must be maintained at a $\mathrm{pH}<3$ to stabilize the $\mathrm{Fe}^{3+}$ ions, which would otherwise hydrolyze to form $\mathrm{Fe}(\mathrm{OH})_{3}$ precipitates. Conversely, the anode solution is generally unstable in the acidic $\mathrm{pH}$ range, as the redox potential of Fe deposition is such that the hydrogen evolution reaction is thermodynamically favored [18-20]. Intuitively, these opposing operating conditions means it is extremely difficult to maintain a $\mathrm{pH}$ gradient between the two electrodes, often requiring additional system components to do so.

Various approaches have been employed to stabilize both the cathodic and anodic solutions and reactions. Ascorbic acid was found effective to suppress hydrogen evolution at the anode side during charging over the $\mathrm{pH}$ range of 0 to 3 [19]. Several ligands, such as citrate, DMSO, glycerol, glycine, malic acid, malonic acid, and xylitol, have been employed to stabilize Fe(III) in aqueous solutions; however, they will also impact the electro-kinetics of the Fe(II)/Fe(III) redox couple [21]. Active balancing systems were designed to maintain the $\mathrm{pH}$ difference between the catholyte and anolyte during cycling [22]. Finally, anion exchange membrane (AEM) should be a potential candidate to mitigate the $\mathrm{pH}$ gradient; however, in the presence of $\mathrm{FeCl}_{3}, \mathrm{Fe}$ (III) spontaneously forms a $\mathrm{FeCl}_{4}{ }^{-}$complex, which leads to rapid fouling and loss of conductivity of the membrane [23]. Besides the $\mathrm{pH}$ issue, chloride-based aqueous solutions are highly 
corrosive to most metals, which prevent the use of low-cost metal parts for the flow battery cell stack [2426]. Due to these challenges, the widespread adoption of $\mathrm{FeCl}_{2}$-based AIFB has been impeded. In contrast, sulfate electrolytes are much less corrosive and more eco-friendly, even for use in waste water cleanup $[16,27]$. However, this salt was not seriously considered in previous decades due to its inferior iron plating qualities and lower solubility, $<1.4 \mathrm{~m}$, compared to ferrous chloride, $>3 \mathrm{~m}$, in aqueous solutions [21,28]. Hence, developing a high-concentration $\mathrm{FeSO}_{4}$ electrolyte is an important research direction for low-cost, long-life all-iron RFBs.

In this study, we report a high concentration $\mathrm{FeSO}_{4} / 1$-ethyl-3-methylimidazolium chloride (EMIC) electrolyte for AIFBs. To accomplish this, 1-ethyl-3-methylimidazolium (EMI $\left.{ }^{+}\right)$is introduced as a minor component to enhance the interaction strength between sulfate ions and water, thereby improving the solubility of $\mathrm{FeSO}_{4}$. The EMIC also serves to improve the uniformity of Fe depositions in the carbon felt, leading to a longer cycle life. Moreover, we show that this new electrolyte composition can enable the operation of the RFB with a low-cost microporous membrane, rather than an expensive ion exchange membrane. Finally, this system was found to be easily regenerated without disassembly, further extending the lifetime of the RFB. These attributes enable us to demonstrate an RFB system with low cost and long service life. 


\section{Materials and methods}

\subsection{Materials}

Ferrous sulfate heptahydrate (Fisher Chemical), ferric sulfate (97\%, Sigma-Aldrich), 1-ethyl-3methylimidazolium chloride (97\%, ACROS ORGANICS), hydrochloric acid (Fisher Chemical), microporous membrane (200 um, Asahi), glass fiber separator (1823-035, Whatman) and soft carbon battery felt (AvCarb C200, FuelCellStore). The carbon felts were pre-oxidized at $400{ }^{\circ} \mathrm{C}$ over 12 hours in the air. All solutions mentioned are prepared with deionized water.

\subsection{Assembly of the lab-scale redox flow battery}

The flow cell was assembled with two carbon felt electrodes sandwiching a microporous membrane. The thickness and compression ratio of the carbon felt electrodes were $6.5 \mathrm{~mm}$ and $30 \%$, respectively. The active area of the flow cell was $4 \mathrm{~cm}^{2}$. Electrolyte was stored in two $20 \mathrm{~mL}$ glass bottles and was circulated through the cell by a Masterflex® L/S ${ }^{\circledR}$ peristaltic pump (Cole-Parmer, Vernon Hills, IL) at a flow rate of $60 \mathrm{~mL} \mathrm{~min}{ }^{-1}$. The electrolytes flowing through the glass bottles were continuously purged with argon to minimize the oxidation of iron species during each measurement. In order to remove entrapped air, electrolyte was circulated through the cell three times in both directions at a flow rate of $120 \mathrm{~mL} \mathrm{~min}^{-1}$ for 5 minutes prior to each measurement. The open circuit voltage of the flow cell should be less than $2 \mathrm{mV}$ since the anolyte and the catholyte are the same solution. All electrochemical tests were conducted at room temperature.

\subsection{Electrochemical measurements}

The electrochemical measurements were recorded by an electrochemical station (VSP-300, Biologic). The battery performance was evaluated within the current density range from $10 \mathrm{~mA} \mathrm{~cm}^{-2}$ to $40 \mathrm{~mA} \mathrm{~cm}^{-2}$. For CE tests, the cells were charged for a fixed time duration (30 mins) and discharged to a voltage limit of 0.3 
V. For cycling stability tests, the cells were charged for 60 mins and discharged to a voltage limit of 0.01 V. For both CE and cycling tests, an upper voltage limit of $2 \mathrm{~V}$ during charging was also imposed even before the time duration was reached. The utilization of the electrolyte was $3.23 \%$ in the CE tests and $7.46 \%$ in the cycling stability tests. The AC impedance was measured from $200 \mathrm{kHz}$ to $10 \mathrm{mHz}$. The cyclic voltammetry measurements were conducted in beaker cells at a scan rate of $10 \mathrm{mV} \mathrm{s}^{-1}$ via a typical threeelectrode system. Graphite electrode (radius $3 \mathrm{~mm}$ ) and platinum wire were selected as the working electrode and counter electrode respectively. $\mathrm{Ag} / \mathrm{AgCl}$ electrode (pre-soaked in potassium chloride solution) was used as the reference electrode. The electrolytes were continuously purged with argon to minimize the oxidation of iron species during each measurement. All electrochemical tests were conducted at room temperature.

\subsection{Characterization}

The morphology and distribution of iron particles in carbon felt was examined via scanning electron microscopy (FEI Apreo). The carbon felt samples were rinsed by deionized water first and then by ethanol and dried by vacuum oven at the room temperature. All figures were taken at a voltage of $5 \mathrm{kV}$ and a beam current of $0.1 \mathrm{nA}$. Conductivity and viscosity of the electrolytes of interest were evaluated using a conductivity meter (PC60-Z, Apera Instruments) and an AR-G2 rheometer (TA Instruments Ltd), respectively.

\subsection{Regeneration process}

The process included pumping out spent electrolyte and then inputting $0.1 \mathrm{M} \mathrm{HCl}$ solution into the flow

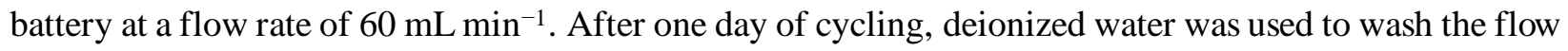
battery until its $\mathrm{pH}$ value is higher than 3.5. After pumping out deionized water, new electrolyte was introduced for the subsequent experiments. The open circuit voltage of the flow cell should be less than 2 $\mathrm{mV}$. 


\section{Theoretical calculations}

The geometries and binding energies $\left(\Delta E_{\text {Binding }}\right)$ were obtained by the density functional theory (DFT) at the B3LYP//6-31+G(d) level of theory in the Q-Chem software. Each geometry optimization cycle was carried out with an SCF convergence of $10^{-7}$ and deemed to reach equilibrium at a convergence of two of the three following factors (with tolerance in parenthesis): maximum gradient $\left(300 \times 10^{-6}\right)$, atomic displacement $\left(1200 \times 10^{-6}\right)$, and energy change $\left(100 \times 10^{-8}\right)$. The binding energies among the sulfate ion, water and $\mathrm{EMI}^{+}$were estimated by Eq. (3):

$$
\Delta E_{\text {Binding }}=E_{\text {complex }}-\left(\sum_{i} E_{\text {components }}\right)
$$

where $E_{\text {complex }}, E_{\text {components }}$, represent the energy of the complex and all components after full geometric relaxation, respectively. 


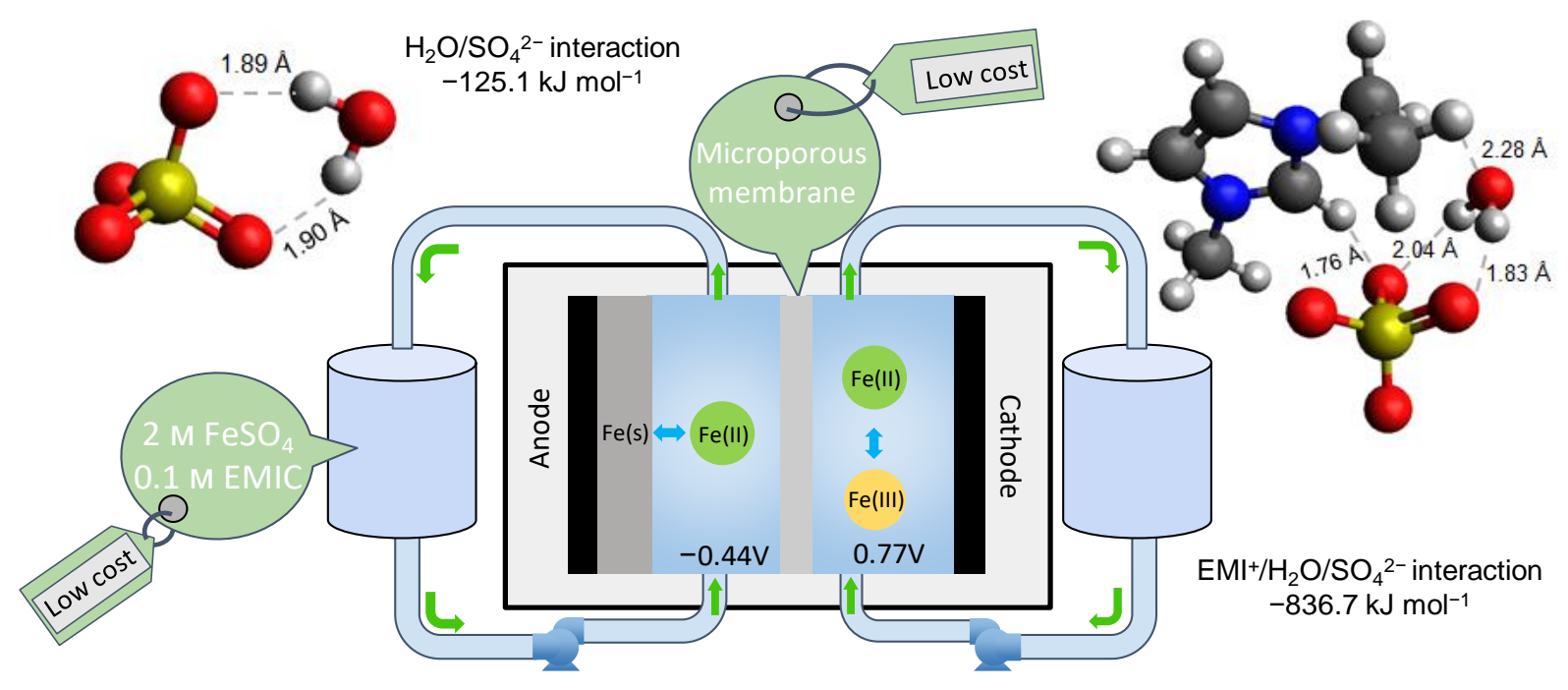

Fig. 1. $\mathrm{FeSO}_{4} / \mathrm{EMIC}$ AIFB chemistry. Schematic diagram of the $\mathrm{FeSO}_{4} / \mathrm{EMIC} \mathrm{AIFB}$ as well as optimized geometries and possible positions for water molecules interacting with sulfate anion with/ EMI cation. Hydrogen bonds are denoted by dashed lines, and the corresponding $\mathrm{H} \cdots \mathrm{O}$ distances are labeled.

\section{Results and Discussion}

\subsection{DFT calculations \& solubility tests: design of high-concentration $\mathrm{FeSO}_{4}$ electrolytes}

A schematic of the $\mathrm{FeSO}_{4} / \mathrm{EMIC}$ all-iron flow battery and the accompanying reversible reactions at each electrode is shown in Fig. 1, which consisted of two carbon felt electrodes sandwiching a microporous membrane. The same electrolyte was stored in the two tanks and circulated through the cell by a peristaltic pump on each side. 
Previously, Zhang et al. reported that 1-ethyl-3-methylimidazolium $\left(\mathrm{EMI}^{+}\right)$enhanced the interaction strength between water and ethyl sulfate at water contents above 60 at $\%$ [29]. Hence, we hypothesized that EMIC, a low-cost imidazolium-based molecule, should also exhibit a similar binding to sulfate, ultimately resulting in an increased solubility of $\mathrm{FeSO}_{4}$ and a correspondingly increased system energy density for the AIFB. To examine this hypothesis, we evaluated the geometries and the binding energies for sulfate anions $\left(\mathrm{SO}_{4}{ }^{2-}\right)$ in water $\left(\mathrm{H}_{2} \mathrm{O}\right)$ with/ $\mathrm{EMI}^{+}$cations via density functional theory (DFT) analysis at the B3LYP//6$31+\mathrm{G}(\mathrm{d})$ level of theory where the optimized geometries and corresponding atomic distances for $\mathrm{SO}_{4}{ }^{2-}-$ $\mathrm{H}_{2} \mathrm{O}$ and $\mathrm{SO}_{4}{ }^{2-}-\mathrm{H}_{2} \mathrm{O}-\mathrm{EMI}^{+}$are shown in Fig. 1. Usually, the small size donor $\mathrm{H}_{2} \mathrm{O}$ should only form hydrogen bond with the aromatic $\mathrm{C} 2-\mathrm{H}$ since it is the most acidic hydrogen on the imidazolium ring [29]. In $\mathrm{SO}_{4}{ }^{2-}-\mathrm{H}_{2} \mathrm{O}-\mathrm{EMI}^{+}$, however, the aromatic $\mathrm{C} 2-\mathrm{H}$ forms a strong hydrogen bond (1.76 $\left.\mathrm{A}\right)$ with $\mathrm{SO}_{4}{ }^{2-}$ and water forms a new hydrogen bond with the ethyl group on the imidazolium ring. This phenomenon can be explained by the strong interaction between $\mathrm{SO}_{4}{ }^{2-}$ and $\mathrm{EMI}^{+}[29]$. The results of DFT calculation indeed showed that while the initial binding energy between $\mathrm{H}_{2} \mathrm{O}$ and $\mathrm{SO}_{4}{ }^{2-}$ is $-125.1 \mathrm{~kJ} \mathrm{~mol}^{-1}$ the addition of $\mathrm{EMI}^{+}$to the complex results in a significantly enhanced binding energy of $-836.7 \mathrm{~kJ} \mathrm{~mol}^{-1}$. Fundamentally, the solubility of a salt in a solvent is defined by the energy required to break the ionic bonds within the salt, which must occur in order to obtain an electrolyte. Generally, the two main factors that contribute to this dissociation are 1) the entropic gain associated with this dissociation, which is represented in the manybody interactions found in the bulk solution, and 2) the enthalpic interactions between the disassociated ions and the species in solution [30]. In this case, we compare the interaction energy between $\mathrm{SO}_{4}{ }^{2-}$ and only the solvent $\left(\mathrm{H}_{2} \mathrm{O}\right)$, and the solvent in the presence of $\mathrm{EMI}^{+}$, where the latter was found to be much stronger. While these cluster calculations do not capture the many-body interactions present in the full electrolyte system, they are heavily indicative of the enthalpic contribution of $\mathrm{EMI}^{+}$on the solvation of $\mathrm{SO}_{4}{ }^{2-}$, which we predict would go on to enhance the $\mathrm{FeSO}_{4}$ solubility.

To confirm these computational results, solutions of $\mathrm{FeSO}_{4}$ with and without the addition of EMIC were tested for their saturation point. A given amount of $\mathrm{FeSO}_{4}$ was dissolved in degassed and deionized water 
at $60{ }^{\circ} \mathrm{C}$. The solution was allowed to equilibrate at room temperature over 24 hours when it was inspected for visible precipitation. The solubility of $\mathrm{FeSO}_{4}$ at room temperature is found to be $\sim 1.4 \mathrm{M}$, which increases to $2.2 \mathrm{M}$ in the presence of $0.1 \mathrm{M}$ EMIC. Though chloride-based salts typically display higher solubilities

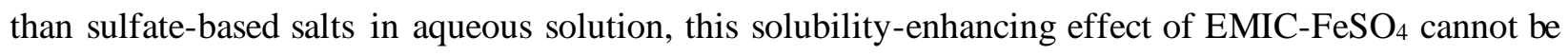
simply explained by the presence of chloride ions, as solutions containing $0.1 \mathrm{M} \mathrm{KCl}$ result in reduced solubilities of 1.7 м. Hence, we conclude that the solvation effect between $\mathrm{EMI}^{+}$and $\mathrm{FeSO}_{4}$ plays a main role in this solubility enhancement.
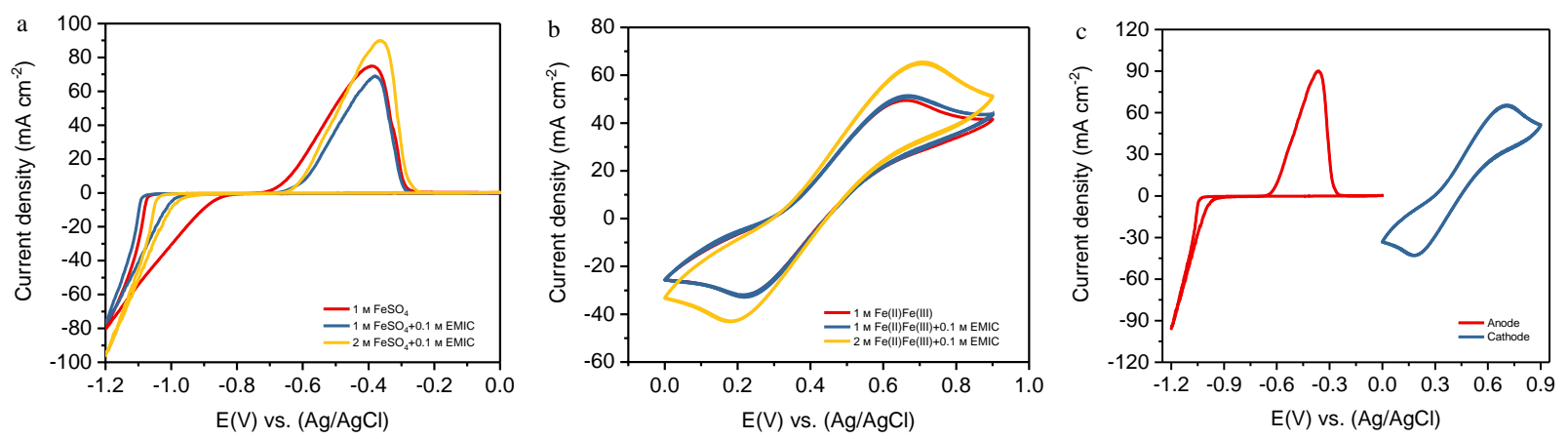

Fig. 2. The electrochemical principle of the redox pair. Cyclic voltammograms of (a) anode, (b) cathode, and (c) full cell, tested in beaker cells at $10 \mathrm{mV} \mathrm{s}^{-1}$, room temperature, in an argon atmosphere. Graphite electrode and platinum wire were selected as the working electrode and counter electrode respectively. $\mathrm{Ag} / \mathrm{AgCl}$ electrode (pre-soaked in potassium chloride solution) was used as the reference electrode.

\subsection{The electrochemical performance of the redox pair}

In most iron-based electrolytes with organic additives, the binding between ligands and iron ions typically results in significant negative effects on the electrode kinetics and the reaction potential in both anodic and cathodic reactions $[21,28]$. To determine if this trend is applicable, cyclic voltammetry $(\mathrm{CV})$ of the $\mathrm{FeSO}_{4} / \mathrm{EMIC}$ AIFB was carried out with the same solution on both anode and cathode sides, as shown in Fig. 2. In the $1 \mathrm{M} \mathrm{FeSO}_{4}$ electrolyte, the plating and stripping potentials of $\mathrm{Fe}$ was found to be $-1.06 \mathrm{~V}$ and 
$-0.387 \mathrm{~V}$, respectively, while the oxidation and reduction peak potentials was found to be $0.656 \mathrm{~V}$ and $0.232 \mathrm{~V}$ for the $\mathrm{Fe}^{2+} / \mathrm{Fe}^{3+}$, respectively. With the addition of $0.1 \mathrm{M} \mathrm{EMIC,} \mathrm{however,} \mathrm{we} \mathrm{found} \mathrm{that} \mathrm{the} \mathrm{plating}$ and stripping potentials of $\mathrm{Fe}$ as well as the $\mathrm{Fe}^{2+} / \mathrm{Fe}^{3+}$ redox peak potentials were virtually unchanged, indicating that the addition of $\mathrm{EMI}^{+}$has a negligible influence on thermodynamics or the electrochemical kinetics. When the $\mathrm{FeSO}_{4}$ concentration was increased to 2 м in the presence of $0.1 \mathrm{м} \mathrm{EMIC,} \mathrm{the} \mathrm{plating}$ potential was found to be slightly more positive, $-1.03 \mathrm{~V}$, indicating that raising the $\mathrm{FeSO}_{4}$ concentration has a positive influence on Fe plating. The slightly increased peak separation for the $\mathrm{Fe}^{2+} / \mathrm{Fe}^{3+}$ redox couple is related to the slower electrode kinetics, possibly due to the electrolyte's increased viscosity [16]. Viscosity results (Table S1) indeed show that the two low-concentration electrolytes exhibited a similar viscosity, $\sim 1.4 \mathrm{mPa} \cdot \mathrm{s}$, while the high-concentration electrolyte exhibited a higher viscosity, $\sim 3.7 \mathrm{mPa} \cdot \mathrm{s}$. The investigation on half-cell CV tests indicated that the high-concentration $\mathrm{FeSO}_{4} / \mathrm{EMIC}$ electrolyte can function both cathodically and anodically, which provided the foundation for full-cell experiments.

\subsection{Electrochemical performance of AIFB with $\mathrm{FeSO}_{4} / \mathrm{EMIC}$ electrolytes}

Fig. 3a-c exhibits the electrochemical performance of all-iron flow batteries operated with $1 \mathrm{~m} \mathrm{FeSO}, 1 \mathrm{~m}$ $\mathrm{FeSO}_{4}+0.1$ м EMIC, and 2 м FeSO$_{4}+0.1$ м EMIC, respectively. Fig. 3d-e summarize the overpotentials and coulombic efficiencies (CEs) at different current densities with electrolytes of interest. The near linear relationship between overpotential and current density indicates that the charge transfer resistance, likely at the Fe electrode, overwhelms the kinetic behavior of the AIFBs. Adding EMIC reduces the slope slightly, a trend that continues with a higher $\mathrm{FeSO}_{4}$ concentration. These observations are consistent with the $\mathrm{CV}$ results. The $\mathrm{CE}$ values are also higher for the electrolyte with a higher concentration of $\mathrm{FeSO}_{4}$. Batteries with $1 \mathrm{MFeSO}_{4}$ with or without EMIC show nearly identical CE values. This is reasonable since the addition of EMIC has a negligible influence on thermodynamics and the electrochemical kinetics of the Fe redox reactions (Fig. 2). In comparison, the $2 \mathrm{M} \mathrm{FeSO}_{4}+0.1 \mathrm{м}$ EMIC electrolyte produced CEs of $75.5 \%, 82.1 \%$, $79.9 \%, 76.3 \%$ at $10,20,30$, and $40 \mathrm{~mA} \mathrm{~cm}{ }^{-2}$, respectively, indicating that increased $\mathrm{FeSO}_{4}$ concentration 
positively influences both the overpotential and CE values. The optimum efficiency is observed at $20 \mathrm{~mA}$ $\mathrm{cm}^{-2}$, likely due to an interplay between iron morphology and the parasitic reactions associated with iron corrosion and crossover. However, the microporous membrane is not designed to prevent Fe(III) crossover, which is likely responsible for the relatively low CE. Other possible factors include the production of $\mathrm{H}_{2}$ and electrically isolated Fe metal. Higher current density is expected to increase loss due to isolated Fe metal but low current density (and the associated long charging time) may increase crossover and hydrogen evolution. As a result, we observe the optimum CE at a current density of $20 \mathrm{~mA} \mathrm{~cm}^{-2}$, which is chosen to examine the long-term cycling performance.
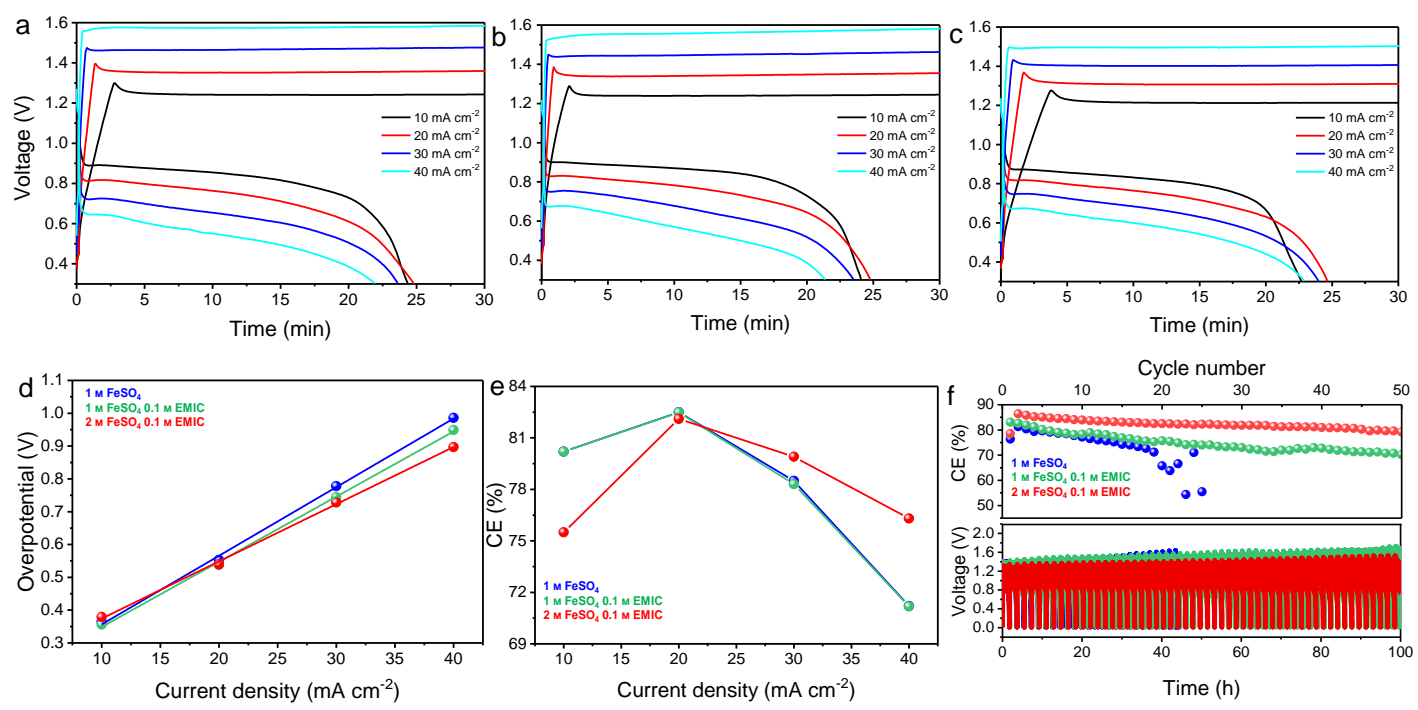

Fig. 3. Electrochemical performance of the $\mathrm{FeSO}_{4}$-based AIFBs. The charge-discharge curves of (a) $1 \mathrm{M}$ $\mathrm{FeSO}_{4}$, (b) 1 м FeSO 4 with 0.1 м EMIC, and (c) $2 \mathrm{M} \mathrm{FeSO}_{4}$ with 0.1 м EMIC electrolytes from $10 \mathrm{~mA} \mathrm{~cm}^{-2}$ to $40 \mathrm{~mA} \mathrm{~cm}^{-2}$. (d) Overpotentials and (e) CEs at different current densities of the three electrolytes. (f) The cycling performance of batteries with the three electrolytes at a current density of $20 \mathrm{~mA} \mathrm{~cm}^{-2}$ and a capacity of $20 \mathrm{mAh} \mathrm{cm}^{-2}$. 
Fig. 3f shows the cycling performance of the flow cells with the electrolytes of interest at a current density of $20 \mathrm{~mA} \mathrm{~cm}^{-2}$ for $20 \mathrm{mAh} \mathrm{cm}^{-2}$. When employing the $1 \mathrm{~m} \mathrm{FeSO}_{4}$ electrolyte, the AIFB was found to suffer from deteriorating $\mathrm{CE}$, reaching its end of life in 18 cycles. With the addition of $0.1 \mathrm{~m}$ EMIC to the electrolyte, the AIFB was found to greatly improve its cycling life, where the initial CE was comparable to the $\mathrm{FeSO}_{4}$ system. The $2 \mathrm{M} \mathrm{FeSO}_{4}+0.1$ м EMIC electrolyte was found to provide both the highest initial and retained $\mathrm{CE}$, with little change in polarization over 50 cycles.

\subsection{Degradation analysis}

Based on the results of cycling performance, AIFBs potentially failed either from iron dendrite penetration of the separator membrane, resulting in internal shorting, and/or a pH imbalance across the separator leading to $\mathrm{Fe}(\mathrm{OH})_{3}$ precipitation on the membrane, resulting in high cell impedance. Of note, the $\mathrm{pH}$ value of $2 \mathrm{~m}$ $\mathrm{FeSO}_{4}+0.1 \mathrm{~m}$ EMIC is 3.43. After the cycling tests (Figure 3f), the $\mathrm{pH}$ of the catholyte decreased to 2.13 while the $\mathrm{pH}$ of the anolyte remained virtually unchanged at 3.39, where the crossed Fe(III) ions are not stable and expected to precipitate out as $\mathrm{Fe}(\mathrm{OH})_{3}$. The expanded view of the charge-discharge profiles in the final cycles prior to failure for the cells shown in Fig. 3f are shown in Fig. S1, where it can be observed that the cell utilizing the $1 \mathrm{~m} \mathrm{FeSO} 4$ electrolyte failed due to internal shorts. However, in the presence of 0.1 м EMIC, such internal shorting was not observed, instead the degradation was found to be a result of rising impedance and a larger IR drop triggering the voltage limit (2V). However, it was found that the $2 \mathrm{M}$ $\mathrm{FeSO}_{4}+0.1$ м EMIC again produced internal shorting. It is thus important to examine the role of EMIC in mitigating shorting. 


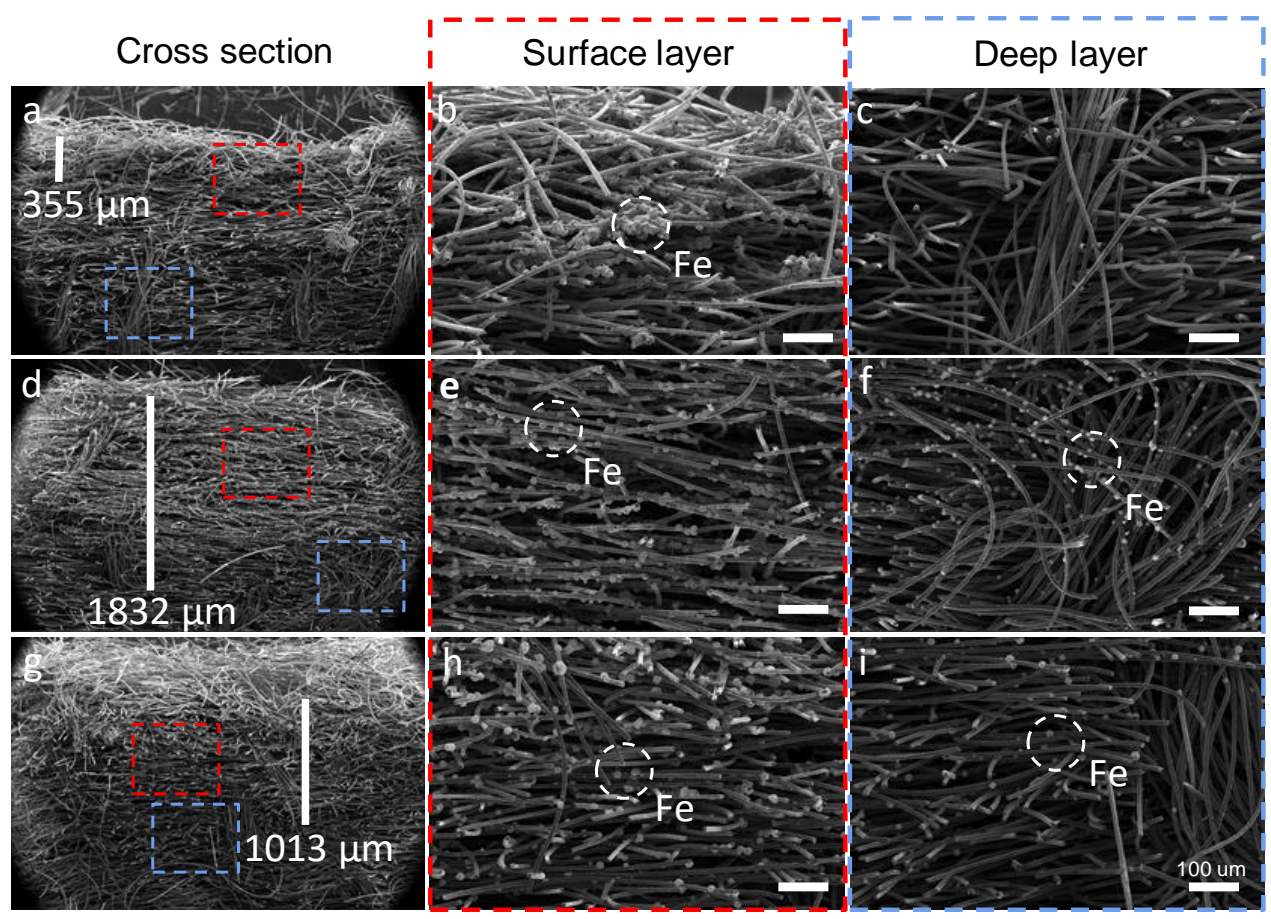

Fig. 4. Iron distribution in the $\mathrm{FeSO}_{4}$-based AIFBs. Iron distribution in carbon felts in (a)-(c) $1 \mathrm{M} \mathrm{FeSO}_{4}$, (d)-(f) 1 м FeSO 4 with 0.1 м EMIC, and (g)-(i) 2 м FeSO 4 with 0.1 м EMIC electrolytes, respectively. All samples were fabricated at $20 \mathrm{~mA} \mathrm{~cm}^{-2}$, one hour.

In all three electrolytes, the plated Fe particles were found to present similar morphology, as shown in Fig. S2. However, the distribution of iron particles in the carbon felt was found to vary depending on the electrolyte, as shown in Fig. 4. In $1 \mathrm{M} \mathrm{FeSO}_{4}$, Fe deposits largely accumulated near the surface (with a depth of $~ 355 \mathrm{um}$ ), which agrees with a previous report from Narelle et al. [31]. In this study, it was also found that these surface depositions readily lead to membrane clogging and even soft shorting. In contrast, with the addition of $0.1 \mathrm{~m}$ EMIC, Fe particles were found to be distributed uniformly down to a depth of $\sim 1832$ um with no obvious Fe clustering in the carbon felt. The effect of the EMIC also persists in the $2 \mathrm{M} \mathrm{FeSO}_{4}$ 
electrolyte with a Fe distribution depth of $\sim 1013$ um. Hence, we believe that the increased uniformity of Fe deposition in the carbon felt is vital to slow the process of soft short and membrane clogging, leading to a longer cycle life. The factors responsible for the more uniform Fe deposition in the presence of EMIC require further investigation. Since that the iron redox electrochemistry and iron particle morphology appear to be independent of the presence of EMIC, we posit that EMIC might improve electrolyte wetting of the 3D carbon felt network, leading to more uniform deposition. Further, the strong interaction between EMI ${ }^{+}$ and $\mathrm{SO}_{4}{ }^{2-}$ might also weaken the ion pairing of $\mathrm{Fe}(\mathrm{II})$ and $\mathrm{SO}_{4}{ }^{2-}$, thus facilitating Fe nucleation.

\subsection{Regeneration process: extend the service life of AIFB with $\mathrm{FeSO}_{4} / \mathrm{EMIC}$ electrolytes}

An ideal low-cost flow battery should contain not only low-cost materials but also low operating and maintenance costs. To satisfy this requirement, we also demonstrate a simple, low-cost regeneration process that yields an extended service life. As we have established that AIFB performance degradation usually manifests as a rise in impedance and/or soft shorting, we drained the electrolyte from the flow battery and rinsed the system with a $0.1 \mathrm{~m} \mathrm{HCl}$ solution in order to remove isolated Fe that risk puncturing the separator, as well as the removal of $\mathrm{Fe}(\mathrm{OH})_{3}$ deposits from the cathode side. The battery was then rinsed with water until the effluent solution reached a $\mathrm{pH}$ value of 3.5 so that the residual $\mathrm{HCl}$ in the battery is expected to be minimal. We envision the spent solution from washing will be recycled in an industrial setting [32]. In order to measure the effects of this replenishment method, electrochemical impedance spectroscopy (EIS) was performed before and after replenishment (Fig. S3). The resistances $\mathrm{R}_{1}$ to $\mathrm{R}_{3}$ are attributed to the electrolyte, the charge-transfer and the diffusion processes, respectively [33]. After 81 cycles, $\mathrm{R}_{1}$ increased from $\sim 0.8$ ohm to $\sim 2.6 \mathrm{ohm}$ and $\mathrm{R}_{3}$ increased from $\sim 0.4 \mathrm{ohm}$ to $\sim 3.3 \mathrm{ohm}$, which can be explained by the formation of inaccessible $\mathrm{Fe}$ and $\mathrm{Fe}(\mathrm{OH})_{3}$ at the anode/membrane interface. After replenishment, $\mathrm{R}_{1}$ and $\mathrm{R}_{3}$ of the cell reverted to values similar as the freshly assembled flow battery. This indicates that any degradation associated with inaccessible $\mathrm{Fe}$ deposits and $\mathrm{Fe}(\mathrm{OH})_{3}$ formation is recoverable. However, it is noteworthy that cells that were replenished after soft shorting events did not recover in the same manner, indicating that 
the iron dendrites inflict irreversible damage to the separator (Fig. S4).

In order to prevent this possible damage to the membrane, we inserted a commercial glass fiber separator (GF membrane) between the carbon felt (anode) and microporous membrane. With the application of this secondary separator, the AIFB was found to cycle over 150 times, three times longer than when the glass fiber separator was absent (Fig. 3f). In addition, the cell overpotential was also significantly improved, only displaying $0.403 \mathrm{~V}$ and a CE value of $87.7 \%$ at a current density of $20 \mathrm{~mA} \mathrm{~cm}^{-2}$. The performance and lifetime improvements are likely related to the reduced probability of Fe dendrite penetration.

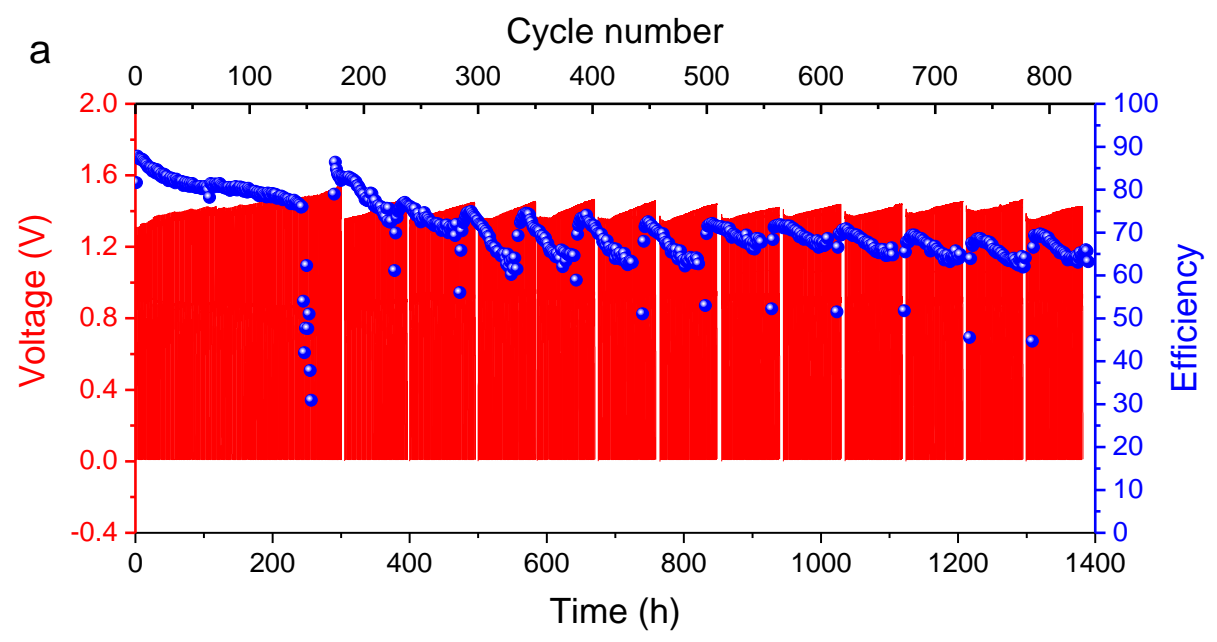

b

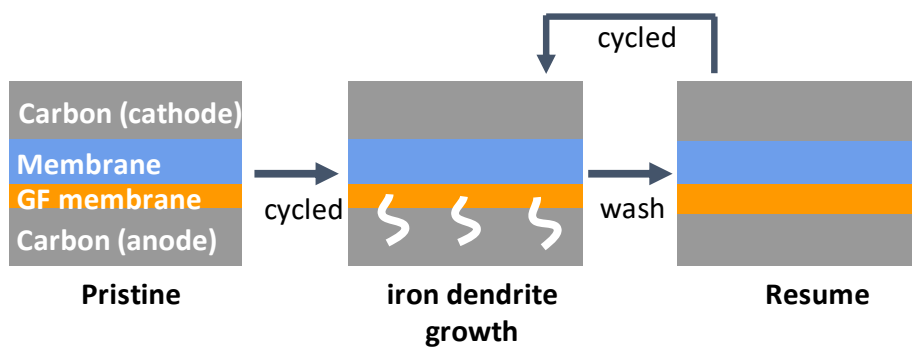

Fig. 5. Regeneration process. (a) The cycling performance of a flow cell with periodic regeneration with 2 м $\mathrm{FeSO}_{4}$ and 0.1 м EMIC electrolyte at a current density of $20 \mathrm{~mA} \mathrm{~cm}^{-2}$ and a capacity of $20 \mathrm{mAh} \mathrm{cm}^{-2}$ and (b) Schematic diagram of battery regeneration. 
Finally, we demonstrate that this regeneration technique can be applied many times successively on the same AIFB. As shown in Fig. 5, the flow battery was successfully regenerated every 50 cycles (twelve times total), delivering over 800 cycles with a stable coulombic efficiency of $70 \%$. After each regeneration process, the overpotential recovered to its original level, $\sim 0.4 \mathrm{~V}$, which gradually increased to $\sim 0.57 \mathrm{~V}$ during subsequent cycles. Additionally, the $\mathrm{CE}$ also recovered to its original value upon regeneration, $\sim 73 \%$, which gradually decreased to $\sim 65 \%$ during cycling. There was no obvious change in the charge-discharge profiles after repeated regeneration. Hence, we believe that this facile, low-cost regeneration process represents a reliable way to substantially improve the cycle life of the $\mathrm{FeSO}_{4} / \mathrm{EMIC}$ AIFB system, which in itself is a substantial improvement from the state-of-the-art. The main compositions of spent electrolyte are $\mathrm{FeSO}_{4}, \mathrm{Fe}_{2}\left(\mathrm{SO}_{4}\right)_{3}, \mathrm{EMIC}$ and $\mathrm{Fe}$-based hydroxides. This mixture is potentially regenerated by acidic rinsing and/or electroreduction.

\subsection{Cost analysis}

To put the performance of the $\mathrm{FeSO}_{4} / \mathrm{EMIC}$ all-iron flow battery into context, a summary of AIFBs is shown in Table S1. Although much progress has been made to understand and mitigate the $\mathrm{pH}$ imbalance issue in AIFBs, operating a stable AIFB without a pH rebalancing system is still a huge challenge. In this work, the high-concentration $\mathrm{FeSO}_{4} / \mathrm{EMIC}$ system exhibited not only stable cycling performance but also a distinct advantage in terms of system cost $\left(\mathrm{C}_{\mathrm{sys}}\right)$, which mainly includes the cost of electrolyte and stack, and can be calculated by Eq. (4) [34]:

$$
C_{s y s} \approx C_{e}+C_{s}=\frac{U_{e}}{V_{e f f}}+\frac{U_{s}}{t \cdot I \cdot V_{e f f}}
$$

where $C_{e}$ and $C_{s}$ are the electrolyte and stack cost per $\mathrm{kWh}\left(\$ \mathrm{kWh}^{-1}\right)$, respectively. $\mathrm{Ue}\left(\$ \mathrm{Ah}^{-1}\right)$ is the cost of the electrolyte per Ah, including the redox species, the additive and the supporting electrolyte. Us $\left(\$ \mathrm{~m}^{-2}\right)$ is the cost of the stack per $\mathrm{m}^{2}$, including the membrane, the electrode and the bipolar plates. $\mathrm{V}_{\text {eff }}(\mathrm{V})$ is the effective discharge cell voltage, and $\mathrm{t}(\mathrm{h})$ is the designed discharge time of the stack and $\mathrm{I}\left(\mathrm{A} \mathrm{m}^{-2}\right)$ is the 
current density.

Based on this equation, we compared the cost structure of all-vanadium (all-V), $\mathrm{Zn}$-Fe, and FeSO $4 / \mathrm{EMIC}^{-}$ RFBs, as summarized in Table 1 and Table S3-8. All-V RFBs exhibit not only the highest electrolyte cost, $64 \$ \mathrm{kWh}^{-1}$, but also the highest stack cost, $695 \$ \mathrm{~m}^{-2}$, since vanadium-based salts and CEMs are expensive. On the other hand, the electrolyte cost of $\mathrm{Zn}-\mathrm{Fe}$ and $\mathrm{FeSO}_{4} / \mathrm{EMIC} \mathrm{RFBs}$ are only $15 \$ \mathrm{kWh}^{-1}$ and 3.37 $\$ \mathrm{kWh}^{-1}$, respectively. Meanwhile, the use of porous membranes further contributes to the low stack cost of these two systems: $\mathrm{Zn}-\mathrm{Fe}$ and $\mathrm{FeSO}_{4} / \mathrm{EMIC}$ RFBs are $259.7 \$ \mathrm{~m}^{-2}$ and $135.1 \$ \mathrm{~m}^{-2}$, respectively, as shown in Table 1.

\begin{tabular}{ccccc}
\hline & $\mathrm{C}_{\mathrm{e}}\left[\$ \mathrm{kWh}^{-1}\right]$ & Membrane $\left[\$ \mathrm{~m}^{-2}\right]$ & $\mathrm{U}_{\mathrm{s}}\left[\$ \mathrm{~m}^{-2}\right]$ & Energy density $\left[\mathrm{Wh} \mathrm{L}^{-1}\right]$ \\
\hline $\mathrm{All}-\mathrm{V}^{\mathrm{a})}$ & 64 & 500 & 695 & $25^{\text {d) }}$ \\
$\mathrm{Zn}-\mathrm{Fe}^{\text {b) }}$ & 15 & 50 & 259.7 & $37^{\text {d) }}$ \\
$\mathrm{FeSO}_{4} / \mathrm{EMIC}^{\text {c) }}$ & 3.37 & 10.1 & 135.1 & $32^{\text {d) }}$ \\
\hline
\end{tabular}

a) Reference [34]; b) Reference [35]; c) The price information and detailed calculation are shown in Table S5 and Table S6; ${ }^{\text {d) }}$ Energy density analysis is shown in Table S9.

Table 1. Electrolyte, membrane, stack cost analysis and energy densities of all- $\mathrm{V}, \mathrm{Zn}-\mathrm{Fe}$, and $\mathrm{FeSO}_{4} / \mathrm{EMIC}$ RFBs.

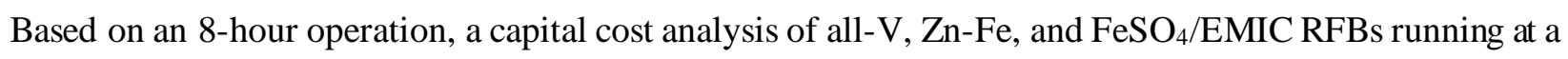
current density of $40 \mathrm{~mA} \mathrm{~cm}^{-2}$ shows that the system cost of all-V, Zn-Fe, and $\mathrm{FeSO}_{4} / \mathrm{EMIC}$ RFBs are 236 
$\$ \mathrm{kWh}^{-1}, 71 \$ \mathrm{kWh}^{-1}[35]$ and $50 \$ \mathrm{kWh}^{-1}$, respectively. The corresponding capital costs are $\sim 500 \$ \mathrm{kWh}^{-1}$ [35], $\sim 82 \$ \mathrm{kWh}^{-1}$ (with 86\% energy efficiency) [35] and $\sim 104 \$ \mathrm{kWh}^{-1}$ (with $48 \%$ energy efficiency, Fig. S5), respectively. Note that this capital cost is defined as system cost divided by energy efficiency, which does not include the cost of other materials/handling (including tanks, pumps, piping, power electronics, etc.). Admittedly, the low energy efficiency of $\mathrm{FeSO}_{4} / \mathrm{EMIC} \mathrm{RFB}$ is largely due to its large overpotential, which is expected to be improved by further reducing the cell resistance via functional membranes and electrode engineering [36-39]. Finally, the actual life-time cost of RFBs also depends on long-term durability and operational costs. The regeneration technology developed here represents a promising strategy to reduce the total cost of $\mathrm{FeSO}_{4} / \mathrm{EMIC}$ RFBs due to its ease of process integration and low-cost materials.

\section{Conclusions}

In summary, an RFB with a high-concentration $\mathrm{FeSO}_{4} / \mathrm{EMIC}$ electrolyte has been demonstrated. The use of EMIC makes two improvements on $\mathrm{FeSO}_{4}$-based RFBs: (i) EMI ${ }^{+}$can strengthen the interaction between sulfate anions and water molecules resulting in an increased solubility of $\mathrm{FeSO}_{4}$ and a correspondingly increased system energy density; and (ii) EMIC can improve the iron metal deposit distribution in carbon felt electrodes and mitigate soft short and membrane clogging, extending cell cycle life. The 2 м $\mathrm{FeSO}_{4} / \mathrm{EMIC} \mathrm{RFB}$ exhibited a competitive theoretical energy density of $32 \mathrm{Wh} \mathrm{L}^{-1}$, achieved a coulombic efficiency of $70 \%$ at $20 \mathrm{~mA} \mathrm{~cm}^{-2}$ and was able to operate stably for more than 800 cycles with no obvious

performance decay via a simple, periodic regeneration process. Meanwhile, the system and capital cost of the $\mathrm{FeSO}_{4} / \mathrm{EMICRFB}$ are estimated to be $\$ 50$ per $\mathrm{kWh}$ and $\$ 104$ per $\mathrm{kWh}$, respectively, among the lowest reported. This low-cost all-iron RFB is a promising stationary energy-storage device for storing renewable energy.

\section{Acknowledgements}


S.Y. and X.Y. contributed equally. S.Y., X.Y. and P.L. conceived the original idea and initial experimental plan. P.L. directed the project. S.Y., and E.P. carried out the experiments. J.H. and T.P. carried out the DFT calculations. X.X. assisted with characterization. S.Y., P.L., and J.H. wrote the paper. All authors discussed the results and commented on the manuscript. We acknowledge the support from Karen L. Christman and Jervaughn Hunter of UCSD for performing viscosity tests. Financial support for this work was provided by the U.S. DOE ARPA-E under Agreement DE-AR0000770.

\section{References}

[1] M. Park, J. Ryu, W. Wang, J. Cho, Material design and engineering of next-generation flow-battery technologies, Nature Reviews Materials. 2 (2016) 1-18.

[2] G.L. Soloveichik, Flow batteries: current status and trends, Chemical Reviews. 115 (2015) 1153311558.

[3] J.F. Weaver, World's largest battery: 200MW/800MWh vanadium flow battery - site work ongoing, (2017). https://electrek.co/2017/12/21/worlds-largest-battery-200mw-800mwh-vanadium-flowbattery-rongke-power/.

[4] T. SHIGEMATSU, Recent Development Trends of Redox Flow Batteries, SEI TECHNICAL REVIEW. (2019) 5.

[5] M. Bon, T. Laino, A. Curioni, M. Parrinello, Characterization of vanadium species in mixed chloride-sulfate solutions: An ab initio metadynamics study, The Journal of Physical Chemistry C. 120 (2016) 10791-10798.

[6] S. Kim, M. Vijayakumar, W. Wang, J. Zhang, B. Chen, Z. Nie, F. Chen, J. Hu, L. Li, Z. Yang, Chloride supporting electrolytes for all-vanadium redox flow batteries, Physical Chemistry Chemical Physics. 13 (2011) 18186-18193.

[7] Y. Yang, Y. Zhang, T. Liu, J. Huang, Improved broad temperature adaptability and energy density of vanadium redox flow battery based on sulfate-chloride mixed acid by optimizing the concentration of electrolyte, Journal of Power Sources. 415 (2019) 62-68.

[8] S. Jin, E.M. Fell, L. Vina-Lopez, Y. Jing, P.W. Michalak, R.G. Gordon, M.J. Aziz, Near Neutral pH Redox Flow Battery with Low Permeability and Long-Lifetime Phosphonated Viologen Active Species, Advanced Energy Materials. 10 (2020) 2000100. https://doi.org/10.1002/aenm.202000100.

[9] L. Li, S. Kim, W. Wang, M. Vijayakumar, Z. Nie, B. Chen, J. Zhang, G. Xia, J. Hu, G. Graff, J. Liu, Z. Yang, A stable vanadium redox-flow battery with high energy density for large-scale energy storage, Advanced Energy Materials. 1 (2011) 394-400. https://doi.org/10.1002/aenm.201100008.

[10] M. Skyllas-Kazacos, L. Cao, M. Kazacos, N. Kausar, A. Mousa, Vanadium electrolyte studies for the vanadium redox battery - a review, ChemSusChem. 9 (2016) 1521-1543.

[11] W. Wang, Q. Luo, B. Li, X. Wei, L. Li, Z. Yang, Recent progress in redox flow battery research and development, Advanced Functional Materials. 23 (2013) 970-986. 
[12] L. Zhang, Y. Qian, R. Feng, Y. Ding, X. Zu, C. Zhang, X. Guo, W. Wang, G. Yu, Reversible redox chemistry in azobenzene-based organic molecules for high-capacity and long-life nonaqueous redox flow batteries, Nature Communications. 11 (2020) 1-11.

[13] O.C. Esan, X. Shi, Z. Pan, X. Huo, L. An, T.S. Zhao, Modeling and Simulation of Flow Batteries, Advanced Energy Materials. (2020) 2000758. https://doi.org/10.1002/aenm.202000758.

[14] A.A. Yaroshevsky, Abundances of chemical elements in the Earth's crust, Geochemistry International. 44 (2006) 48-55.

[15] K. Gong, F. Xu, J.B. Grunewald, X. Ma, Y. Zhao, S. Gu, Y. Yan, All-soluble all-iron aqueous redoxflow battery, ACS Energy Letters. 1 (2016) 89-93.

[16] M.C. Tucker, A. Phillips, A.Z. Weber, All-iron redox flow battery tailored for off-grid portable applications, ChemSusChem. 8 (2015) 3996-4004.

[17] L.W. Hruska, R.F. Savinell, Investigation of factors affecting performance of the iron-redox battery, Journal of The Electrochemical Society. 128 (1981) 18.

[18] S. Selverston, Iron-Based Flow Batteries: Improving Lifetime and Performance, Case Western Reserve University, 2017.

[19] B.S. Jayathilake, E.J. Plichta, M.A. Hendrickson, S.R. Narayanan, Improvements to the coulombic efficiency of the iron electrode for an all-iron redox-flow battery, Journal of The Electrochemical Society. 165 (2018) A1630.

[20] P. Ke, K. Song, Z. Liu, Encapsulation of scorodite using crystalline polyferric sulfate precipitated from the Fe (II)-SO42--O2-H2O system, Hydrometallurgy. 180 (2018) 78-87.

[21] K.L. Hawthorne, J.S. Wainright, R.F. Savinell, Studies of iron-ligand complexes for an all-iron flow battery application, Journal of The Electrochemical Society. 161 (2014) A1662-A1671.

[22] S. Selverston, E. Nagelli, J.S. Wainright, R.F. Savinell, All-Iron Hybrid Flow Batteries with In-Tank Rebalancing, Journal of The Electrochemical Society. 166 (2019) A1725-A1731. https://doi.org/10.1149/2.0281910jes.

[23] M.J. McGrath, N. Patterson, B.C. Manubay, S.H. Hardy, J.J. Malecha, Z. Shi, X. Yue, X. Xing, H.H. Funke, D.L. Gin, P. Liu, R.D. Noble, 110th Anniversary: The Dehydration and Loss of Ionic Conductivity in Anion Exchange Membranes Due to FeCl4- Ion Exchange and the Role of Membrane Microstructure, Industrial and Engineering Chemistry Research. 58 (2019) 22250-22259. https://doi.org/10.1021/acs.iecr.9b04592.

[24] V. Guillaumin, G. Mankowski, Localized corrosion of 2024 T351 aluminium alloy in chloride media, Corrosion Science. 41 (1998) 421-438.

[25] G.K. Glass, N.R. Buenfeld, The influence of chloride binding on the chloride induced corrosion risk in reinforced concrete, Corrosion Science. 42 (2000) 329-344.

[26] S. Pal, S.S. Bhadauria, P. Kumar, Pitting corrosion behavior of F304 stainless steel under the exposure of ferric chloride solution, Journal of Bio-and Tribo-Corrosion. 5 (2019) 91.

[27] J. Datta, C. Bhattacharya, S. Bandyopadhyay, Influence of Cl-, Br-, NO 3-and SO 4 2-ions on the corrosion behaviour of $6061 \mathrm{Al}$ alloy, Bulletin of Materials Science. 28 (2005) 253-258.

[28] K.L. Hawthorne, T.J. Petek, M.A. Miller, J.S. Wainright, R.F. Savinell, An investigation into factors affecting the iron plating reaction for an all-iron flow battery, Journal of The Electrochemical Society. 162 (2015) A108-A113.

[29] Q.-G. Zhang, N.-N. Wang, Z.-W. Yu, The hydrogen bonding interactions between the ionic liquid 1-ethyl-3-methylimidazolium ethyl sulfate and water, The Journal of Physical Chemistry B. 114 (2010) 4747-4754. 
[30] A. Baskin, D. Prendergast, Ion Solvation Engineering: How to Manipulate the Multiplicity of the Coordination Environment of Multivalent Ions, Journal of Physical Chemistry Letters. (2020) 93369343. https://doi.org/10.1021/acs.jpclett.0c02682.

[31] N. Brack, P. Kappen, A.I.R. Herries, A. Trueman, A.N. Rider, Evolution of magnetic and structural properties during iron plating of carbon nanotubes, The Journal of Physical Chemistry C. 118 (2014) $13218-13227$.

[32] D.M. Allen, L.T. Lerb, Increasing utilisation efficiency of ferric chloride etchant in industrial photochemical machining, n.d. http://www.rsc.org/suppdata/em/1999/103.

[33] V. Yufit, B. Hale, M. Matian, P. Mazur, N.P. Brandon, Development of a Regenerative HydrogenVanadium Fuel Cell for Energy Storage Applications, Journal of The Electrochemical Society. 160 (2013) A856-A861. https://doi.org/10.1149/2.086306jes.

[34] K. Gong, X. Ma, K.M. Conforti, K.J. Kuttler, J.B. Grunewald, K.L. Yeager, M.Z. Bazant, S. Gu, Y. Yan, A zinc-iron redox-flow battery under $\$ 100$ per $\mathrm{kW}$ h of system capital cost, Energy \& Environmental Science. 8 (2015) 2941-2945. https://doi.org/10.1039/c5ee02315g.

[35] C. Xie, Y. Duan, W. Xu, H. Zhang, X. Li, A Low-Cost Neutral Zinc-Iron Flow Battery with High Energy Density for Stationary Energy Storage, Angewandte Chemie International Edition. 56 (2017) $14953-14957$.

[36] R. Tan, A. Wang, R. Malpass-Evans, R. Williams, E.W. Zhao, T. Liu, C. Ye, X. Zhou, B.P. Darwich, Z. Fan, Hydrophilic microporous membranes for selective ion separation and flow-battery energy storage, Nature Materials. 19 (2020) 195-202.

[37] Q. Dai, Z. Liu, L. Huang, C. Wang, Y. Zhao, Q. Fu, A. Zheng, H. Zhang, X. Li, Thin-film composite membrane breaking the trade-off between conductivity and selectivity for a flow battery, Nature Communications. 11 (2020) 1-9.

[38] Z. He, Y. Jiang, Y. Li, J. Zhu, H. Zhou, W. Meng, L. Wang, L. Dai, Carbon layer-exfoliated, wettability-enhanced, $\mathrm{SO} 3 \mathrm{H}$-functionalized carbon paper: A superior positive electrode for vanadium redox flow battery, Carbon. 127 (2018) 297-304.

[39] A.W. Bayeh, D.M. Kabtamu, Y.-C. Chang, G.-C. Chen, H.-Y. Chen, G.-Y. Lin, T.-R. Liu, T.H. Wondimu, K.-C. Wang, C.-H. Wang, Ta2O5-nanoparticle-modified graphite felt as a highperformance electrode for a vanadium redox flow battery, ACS Sustainable Chemistry \& Engineering. 6 (2018) 3019-3028. 